\title{
Research on Flocculation of Cement Particles in Water
}

\author{
Zuo Yanfeng ${ }^{1}$, Zhang Yijie ${ }^{2}$, and Wang Dongmin ${ }^{3}$ \\ ${ }^{1}$ Department of Civil Engineering, Institute of Disaster Prevention, Langfang, China \\ ${ }^{2}$ School of Civil Engineering \& Transportation, Beijing University of Civil Engineering and Architecture, Beijing, China \\ ${ }^{3}$ School of Chemical \& Environmental Engineering, China Mining \& Technology University(Beijing), Beijing, China
}

\begin{abstract}
Nowadays, workability is absolutely necessary for piping concrete, which is influenced by characteristics of structure of fresh cement paste. In this paper, the movement of particles in electric field and flocculent units at different W/C were observed, and rheologic characteristics of fresh cement paste at different W/C and the pastes with naphthalene sulphonate (NS) and poly carboxylate (PC) superplasticizers were investigated using rotational viscometer (NXS-11A). It is found that at initial hydration age cement particles carry different electric quantity and electrical property; increment of $\mathrm{W} / \mathrm{C}$ induces flocculent units more separated, less hysteresis loop area and lower crush point; application of superplasticizers brings much less loop area and indistinct crush point. It is concluded that 1) fresh cement paste is filled with flocculation units of different strength; 2) different units are connected with one another loosely; 3) tunnels for bleeding form in the weakest connecting area. Water can disperse flocculent units to some extent, especially for superplasticizers. However, the latter can't separate flocculation of cement particles completely.
\end{abstract}

\section{Introduction}

Workability of fresh concrete is required in the process of placing concrete, especially for high-rises[1]. Some of the construction requires self-compacting placement[2]. The factors influencing workability are characters of cement, water content, sand percentage, chemical admixtures[3][4] and so on. Fresh cement paste is cohesive material between fine and coarse aggregates, which affects workability to large extent and is also one of the important sources making fresh concrete flow. Water reducing agent, particularly superplasticizer, can change the structure of cement paste in fresh concrete, and enables concrete to be plasticized.[5][6][7]

Before addition of water, cement particles are separated. Tattersal and Banfill [8] reported that there is weak surface force between the particles and they are connected with each other loosely. After water addition, surface of cement particles is changed, and a type of paste with yields stress, named weak solid by Heimuth [9], establishes. Rheologic characteristics of fresh cement paste are relevant to its inner structure, which is associated with the nature of particles in it.

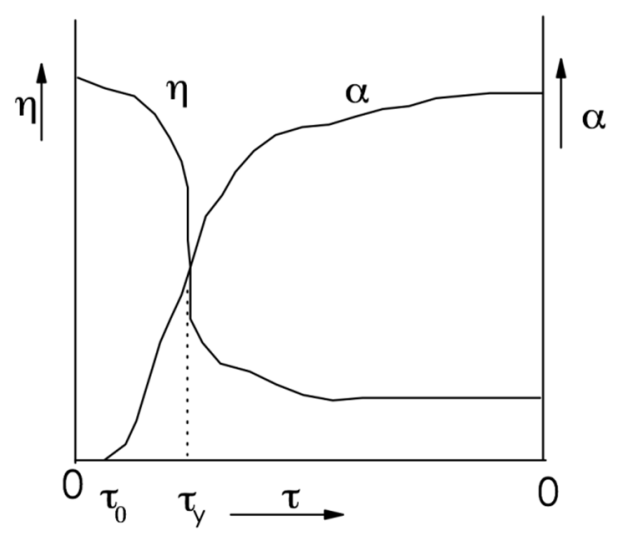

Fig1. Variation of viscosity, shear stress and structure of fresh cement paste.

T.C. Powers's sedimentation experiments [10] showed that in the watery suspension cement particles usually were flocculated and sedimentated sharply. Helmuth [9] considered that water molecules were adsorbed on cement particle surface, and every particle was packed within a continuous water film, and once the paste is stirred or water reducing agent exits, this film would tend to be uniform. Tattersall and Banfill's [8] rheology experiments and SEM observation indicated that hydrate film enwrapped the flocculation structure after cement and water mixed.

Zhang [11] draw a conclusion from the viewpoint of correlation between viscosity and fresh paste structure. His results indicated that viscosity varies with the structure of fresh paste, which is shown in Figure 1. arepresents structure crushing process, and $\eta$ viscosity 
changing process. When shear stress is less than $\tau 0$, structure is not crushed, and while reaching $\tau y$, namely crush point, the structure will be destroyed sharply. If $\tau$ is large enough, viscosity becomes constant, which means the structure is destroyed completely.

This paper would illustrate the formulation of fresh cement paste through rheological and optical method, which is important for design of piping or self-compacting concrete.

\section{Experimental Details}

\subsection{Materials}

Portland cement is applied. And its chemical, mineral content are shown in Table 1 and Table 2.

UNF-5 is $\beta$-naphthalene sulphonate (NS) superplasticizer in powder state. COPOCA202 is poly carboxylate (PC) superplasticizer, in liquid state, and its solid content is $30 \%$. Water reducing effect of the former is $17 \%$ at dosage of $0.70 \%$ (by mass), the latter $26 \%$ at $0.60 \%$ (by solid mass) [12].

Table1. Mineral and chemical components of Portland cement $(\%)$

\begin{tabular}{|c|c|c|c|c|}
\hline $\mathrm{SiO}_{2}$ & $\mathrm{Al}_{2} \mathrm{O}_{3}$ & $\mathrm{Fe}_{2} \mathrm{O}_{3}$ & $\mathrm{CaO}$ & $\mathrm{MgO}$ \\
\hline 21.24 & 4.73 & 2.63 & 63.94 & 1.78 \\
\hline
\end{tabular}

Table2. Mineral and chemical components of Portland cement $(\%)$

\begin{tabular}{|c|c|c|c|c|c|}
\hline $\mathrm{SO}_{3}$ & $\mathrm{Na}_{2} \mathrm{Oeq}$ & $\mathrm{f}-\mathrm{CaO}$ & $\mathrm{C}_{3} \mathrm{~S}$ & $\mathrm{C}_{3} \mathrm{~A}$ & $\begin{array}{c}\text { Ignite } \\
\text { loss }\end{array}$ \\
\hline 2.73 & 0.54 & 1.00 & 54.01 & 7.36 & 2.06 \\
\hline
\end{tabular}

\subsection{Observation of Flocculent Unit}

Cement powder was added in deionized water, stirred for 20 s to a homogenous suspension, a drop of which were left on a glass slide to be investigated. XJZ-6 metallosope was applied to survey the specimens.

As for the observation of interface among flocculent units, extra stewing for 30s is needed. And then filter paper was employed to suck the above water slightly, and the remainder is the sample required.

The experimental temperature was $26^{\circ} \mathrm{C}$.

\subsection{Electric Characters of Cement Particles at Very Early Age}

Cement was added in deionized water, stirring for $20 \mathrm{~s}$. BDL-B zeta potential apparatus was applied. The experiment temperature was $20^{\circ} \mathrm{C}$. W/C is 1000 .

\subsection{Rheologic Characteristics of Fresh Cement}

The fresh cement pastes were agitated for 3 min by a stirring machine at same speed. Rotational viscometer (NXS-11A) was employed to measure rheologic performance. The experimental temperature was $17^{\circ} \mathrm{C}$. The dosages of UNF-5 and COPOCA202 are $0.70 \%$ and
$0.60 \%$ (by solid mass) respectively.

\section{Experimental Results and Discussions}

\subsection{Electric Characteristics of Cement Particles at Very Early Age}

Figure 2 shows that moving directions of particles are different in the electrophoresis tank, and so is velocity, which means some particles present positive, others negative, and the values are also different. And that confirms the different electric characteristics of every cement particles during their initial hydration period.

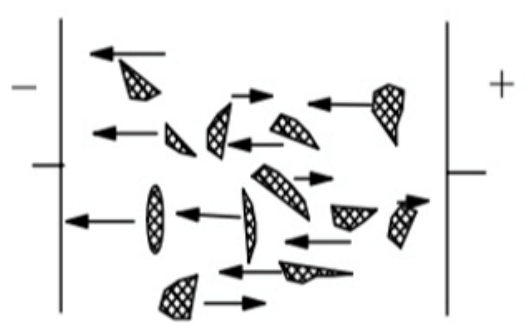

Fig2. Illustration of cement particles movement in electric field.

\subsection{Flocculation of Cement Particles}

From the Figure 3, it is indicated that at $\mathrm{W} / \mathrm{C}=5.0$, structures can't be shown definitely; as for (b), large flocculation units are presented, and small units are filled among large ones; for (c), the units become smaller, and the smallest in (d). Therefore, the strength of flocculation units in fresh cement paste is different. And they can be destroyed progressively by water. Firstly, some of the weak units are crushed and at the same time the rest of harder ones alters to be weak. Then with more water applied, the weaker ones of the former residual are destroyed, and it brings much weakness to the remainder. And the process will cycle until all of them being crushed.

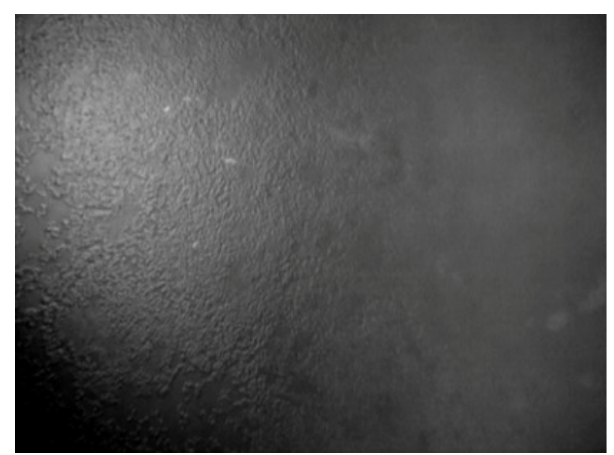

(a) $\mathrm{W} / \mathrm{C}=5.0$ 


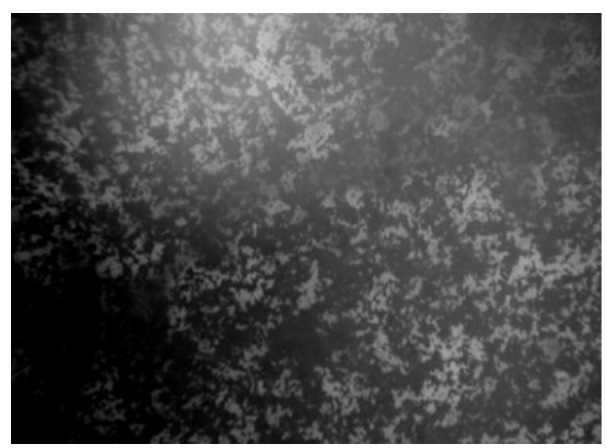

(b) $\mathrm{W} / \mathrm{C}=10.0$

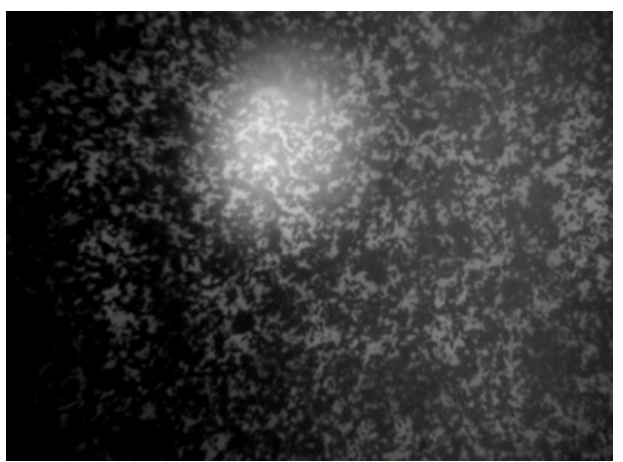

(c) $\mathrm{W} / \mathrm{C}=30.0$

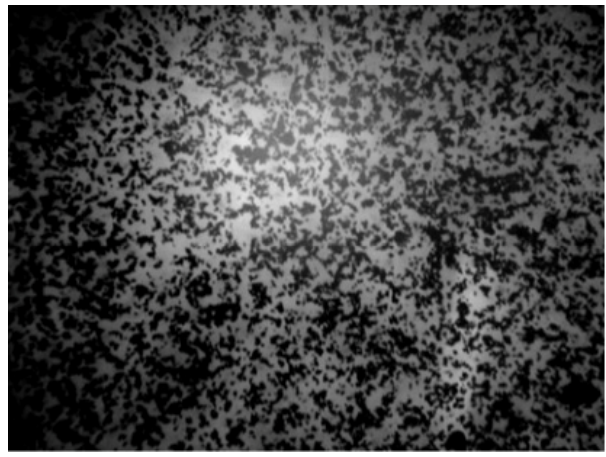

(d) $\mathrm{W} / \mathrm{C}=100.0$

Fig3. Flocculent units at different $\mathrm{W} / \mathrm{C}, 50 \times$.

It is shown in Figure 4 that flocculent units are connected incompactly, which conduces the formation of bleeding tunnels between them.

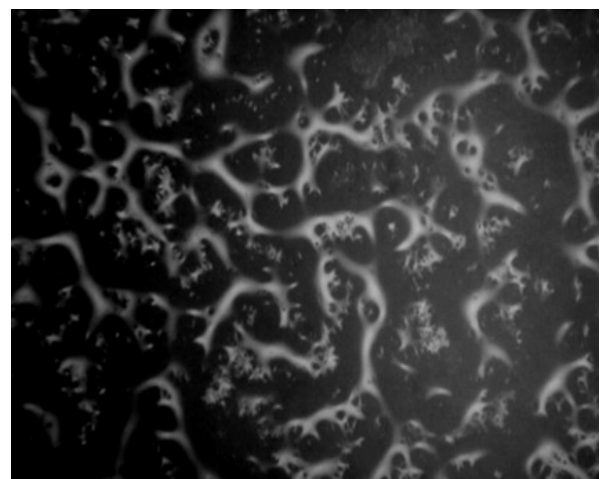

Fig4. Interface between flocculent units, $\mathrm{W} / \mathrm{C}=20.0,50 \times$

\subsection{Rheologic Properties of Fresh Cement Paste}

\subsubsection{Rheologic Characters of Pure Cement Paste}

Typically, fresh cement paste has hysteresis loop, shown in Figure 5, which means that shear rate (DS) increasing process (upward) curve and decreasing (downward) process curve are not in superposition. And it is also indicated that the shear stress of upward process is higher than downward, which is called shear thinning or thixotropy phenomenon. And loop area is considered to represent flocculation degree, and the larger area, the harder flocculation.

With different $\mathrm{W} / \mathrm{C}$, cement paste shows different flocculation. Figure 6 indicates that loop area decreases with $\mathrm{W} / \mathrm{C}$ increasing and so does shear stress at the same shear rate. And in Figure 7, it is shown that with W/C increasing, viscosity decreases at the same shear stress, and crush point also decrease.

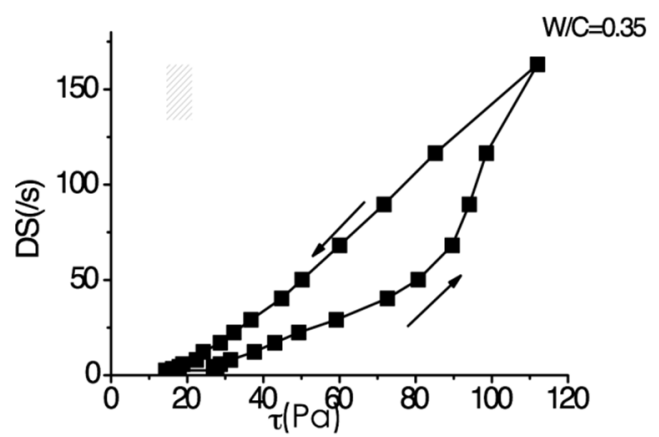

Fig5. Hysteresis loop of fresh cement paste.

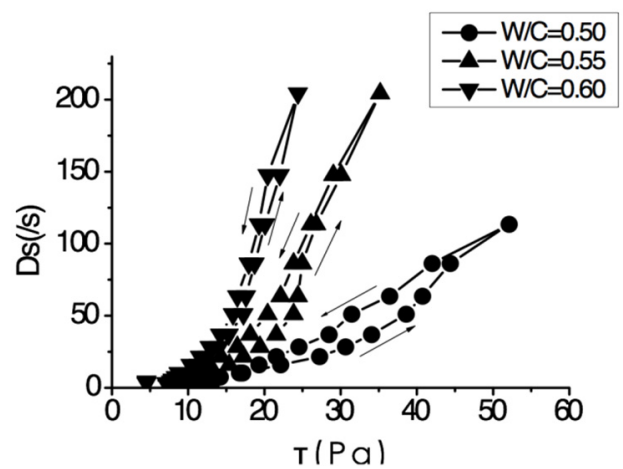

Fig6. Hysteresis loop of fresh cement paste at different W/C.

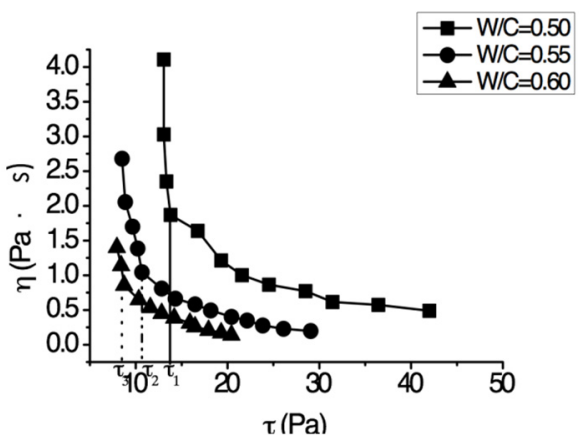

Fig7. Crush point of fresh cement paste at different $\mathrm{W} / \mathrm{C}$, and $\tau_{1}$, $\tau_{2}, \tau_{3}$ are the crush points of paste of $\mathrm{W} / \mathrm{C}=0.50,0.55$, 0.60 respectively. 


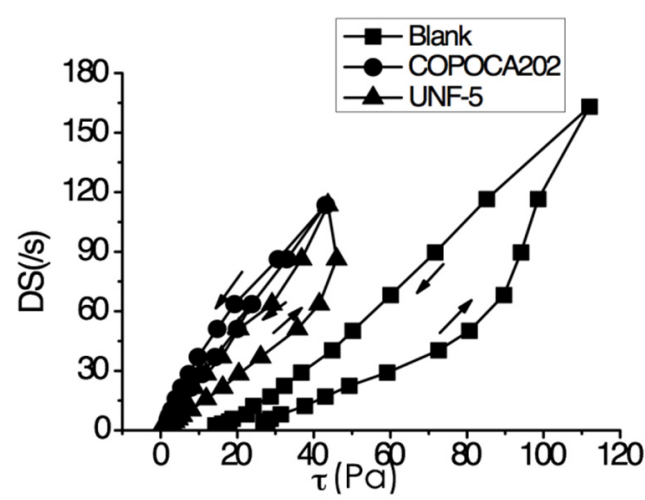

Fig8. Hysteresis loop of fresh cement paste with superplasticizers, $\mathrm{W} / \mathrm{C}=0.35$.

\subsubsection{Rheological Characteristic of Cement Paste with Superplasticizers}

Figure 8 shows that addition of superplasticizer leads to a decrease in the hysteresis loop, and PC superplasticizer with higher water reducing effect shows the least area.

As to Figure 9, viscosity of the samples with superplasticizers is almost unchanged with shear stress increasing compared with blank sample, and the crush points are indistinct either, which means that superplasticizer can destroy flocculation structures to large extent.

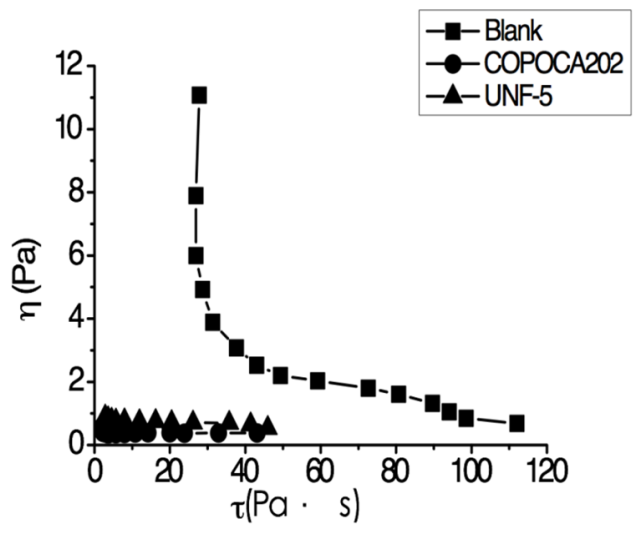

Fig9. Crush point of fresh cement paste with and without superplasticizers.

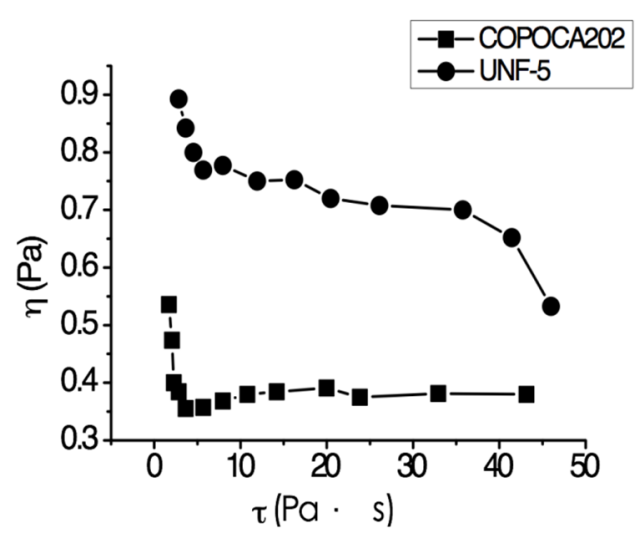

Fig10. Crush point of fresh cement paste with COPOCA202 \& UNF-5.

Figure 10 shows that the specimens with superplasticizers have a similar curve of Figure 1. Namely, superplasticizers just destroy a part of flocculation structures, while the structures with high strength do not diminish and just alters to be weak ones. Compared with Figure 9, Figure 10 indicates that the crush points of the sample with superplasticizers are much smaller than the former, because of the residual infirm structure that can be destroyed by weak shear stress.

At high shear stress, UNF-5 paste exhibits decline of viscosity, which COPOCA202 sample doesn't have. The dispersion of the former is less than the latter, which induces more and stronger flocculent units exiting in UNF-5 specimen. High shear stress destroys them, which brings forth decreasing of viscosity.

\subsection{Discussions}

The size of cement particles is various and the shape is irregular. Moreover, mineral distribution in every particle is nonuniform. Thus, every particle has its own characteristics of hydration process, which makes surface characters (such as electric properties, solvation film, etc) of every particle different. Reports [13-15] show that hydration of aluminate phase contributes to positive electricity, however, silicate phase negative, and at very early stage of hydration cement particles show positive.

After water addition, the aluminate phase in cement particles makes them show positive, and however, some of fine particles containing more silicate phase represent negative. Particles with different sign connect with each other through static electric attractive force, which bring forth flocculent units, and the higher static electric attractive force, the higher strength of the unit. With time elapsing and hydration process going on, gradual formation of hydrates at particle surface will engender chemical osculation once they develop large enough in size. Actually, during the initial hydration period, electric quality and sign of cement particles also vary with time [16], which may influence strength of flocculent unites to some extent.

Therefore, there are two types of important forces during formation of cement paste structure, i.e. static electric attractive force and chemical bond. At the first stage, the former dominates, which generates flocculation; then, the latter plays more important role, which engenders hardened cement paste eventually. Another one for attraction is Van der Waals force, which is much less than electric force at very early age of hydration.

The whole fresh cement paste is filled with different strength flocculation units, which are connected with one another loosely. And tunnels for bleeding form in the weaker connecting area.

During stirring process, weak flocculation structures are crushed fractionally. At higher shear stress, more of them would be crushed. When shear rate decreasing, many of them can't be reconnected, and the whole paste is filled with many separated flocculation units. During downward process, the decreasing shear stress can't crush flocculent units so greatly as that of the upward process, and therefore, the downward curve is more linear with DS than the upward. And because of destruction of large 
flocculation unites, under the condition of same DS, shear stress during downward is lower than upward.

The paste at high $\mathrm{W} / \mathrm{C}$ has more incompact flocculent units whose solidity is lower, and maybe the amount of the units is less than the former. When shear stress acts on the paste with high $\mathrm{W} / \mathrm{C}$, flocculent units are apt to be broken up. And it induces smaller counterforce to balance the outside force, that shows lower shear stress. And also at low shear stress the flocculent units can be destroyed to large extent, which engenders low crush point. If $\mathrm{W} / \mathrm{C}$ is high enough, flocculent units may be destroyed to great extent in stirring period. And the upward line can be near to superposition with the downward one.

Naphthalene sulfate and poly carboxylate superplasticizers are anionic surfactants, which tends to adsorb on positive cement particles, and enlarge repulsive force between them through increasing static-electric or steric repulsive force, which brings forth the destruction of some flocculent units. The adsorption induces identical electric sign of cement particles, which brings difficulty to flocculation for the electric repulsive force between particles. However, Fig. 10 shows that they cannot disperse the flocculent units entirely, and a few very weak ones remain. And PC superplasticizer, which has higher water reducing effect than NS, induce much weaker units than NS. This type of flocculation is maybe formed by collision of particles at their irregular tips or edges. And therefore, they are very weak.

\section{Conclusions}

During the initial hydration period, cement particles show different electrical performance, some carrying positive charge, and some negative, and the electric quantity of every particle is also different, which induces formation of flocculation by static electric attractive force. And collision at the irregular tips or edge of particles is maybe another cause of the formation.

The whole fresh cement paste is filled with flocculation units of different strength. Different units are connected with one another loosely. And tunnels for bleeding form in the weakest connecting area.

During stirring process, a part of weak flocculation structures are been destroyed. With higher shear stress, more of them would be crushed. That is reason why fresh cement paste has hysteresis loop. And the paste with high $\mathrm{W} / \mathrm{C}$ has weak flocculation, which brings a small value of hysteresis loop area and crush point.

The crush point becomes indistinct when superplasticizers are applied, which means they can destroy flocculation structure greatly. Particularly, PC is able to destroy the structures more compared with UNF-5. However, they can't destroy flocculation completely for the existence of crush points.

\section{References}

1. Liu.Rentai,Zhang.Chunyu,Liu.Haojie,Pei.Yan,Li.Xiu hao, Wang.Zhenjun, Effects of flocculation of cement slurry on groutability of porous media Construction and Building Materials, v 233 ( 10 February 2020)

2. Rao.S.Venkateswara.,Rao.M.V.Seshagiri,

Ramaseshu.D,Kumar, P.Rathish, Durability performance of selfcompacting concrete Magazine of Concrete Research, v 64, n 11, p 1005-1013 (November 1, 2012) Construction and Building Materials, v 237 (20 March 2020)

3. Han.Kaidong,Xiao.Jia,Zhang.Zedi,Wang.Jialei,Hu.X iaoyan, Effect of particle size distribution on flocculation and its growth in cement-ground limestone suspensions Construction and Building Materials, v 262 (30 November 2020)

4. Lucia,Influence of superplasticizers on the flocculation degree of cement suspensions Ferrari, Boustingorry, Pascal American Concrete Institute, ACI Special Publication, v 2015 (January,2015)

5. Zeyad, Abdullah M, Almalki.Ali Influence of mixing time and superplasticizer dosage on selfconsolidating concrete properties (Open Access) Journal of Materials Research and Technology (2020)

6. Ma.Baoguo,Qi.Huahui,Tan.Hongbo,Su.Ying,Li.Xian gguo, Liu.Xiaohai, Li.Chunbao, Zhang.Ting, Effect of aliphatic-based superplasticizer on rheological performance of cement paste

7. Ke.Guoju, Zhang.Jun, Journal of Advanced Concrete Technology, v 18, n 1, p 17-26 (January 2020) Effects of retarding admixture, superplasticizer and supplementary cementitious material on the rheology and mechanical properties of high strength calcium sulfoaluminate cement paste

8. G. H. Tattersall and P. E. G. Banfill, Rheology of Fresh Concrete ISBN:0-273-08558-1, Pitman Advanced Publishing Program, Pitman Press (1983).

9. R. A. Heimuth. Flocculation and rheology of fresh cement paste. Chinese version of 7 th international cement chemistry conference collective papers. Beijing: China Architecture \& Building Press (1983)

10. T. C Powers. The bleeding of Portland cement paste, mortar and concrete, ACI Journal, Vol 35, p465-480, (1939).

11. G. L. Zhang, Y. L. Zhang. Principles of Chemical Admixtures for Concrete and Their Application, ISBN: 7-112-00682-1, Shanghai Science \& Technology Press, (1985)

12. Y. F. Zuo, D. M. Wang, S. Z. Wu. Effects of Crosslinking Poly Carboxylate Superplasticizer (COPOCA202) on Fresh Concrete, Annual Conference on Cement Based Materials in 2003. p 418-424, Beijing, China, (Sept 19-21, 2003)

13. Y. F. Zuo. Effects of Poly-carboxylic Superplasticizer on Fresh Concrete and Its Mechanism. Master thesis. Beijing: China Building Materials Academy, (2004)

14. X. C. Hu, C. Y. Liu, B. P. Yao. Effect Mechanism of Water Reducing Agent for Concrete, Proccedings of 1985 Beijing international symposium on cement and concrete, Vol 2, p179-190, Beijing, China, （May 1417, 1985). 
15. J. Plank, C. Hirsh. Impact of zeta potential of early cement hydration phases on superplasticizer adsorption Cement and Concrete Research, Vol 37, No. 4, p 537-542.

16. J. K. Chen. Principles and Application of Chemical Admixtures for Concrete ( $2^{\text {nd }}$ edition) ISBN: 780058-500-X, Chemical Industry Press, ( April 2004). 